\title{
Efektivitas Penerapan Iklan Digital pada Era Marketing 4.0 di Hotel Grand Mirage Resort Bali
}

\author{
I Made Rilo Elton1, I Ketut Surata², I Putu Esa Widaharthana ${ }^{3 *}$ \\ 1,2,3Program Studi Bisnis Hospitaliti, Politeknik Pariwisata Bali \\ Jl. Dharmawangsa, Kampial, Nusa Dua. Ph. (0361) 773537 \\ 1riloelton47@outlook.com, 22surata_iketut@yahoo.com,3*iputuesa@ppb.ac.id \\ *Corresponding author
}

\begin{tabular}{l|l|l} 
Received: Oktober, 2021 & Accepted: Oktober, 2021 & Published: Desember, 2021
\end{tabular}

\begin{abstract}
The development of the industry had evolved to digital marketing, dubbed Marketing 4.0. Nowadays, the use of social media as promotional tool is important. In hospitality industry, hotels are developing their profiles on social media intensively, for example Grand Mirage Resort Bali. In 2017 the hotel finished renovating and rebranding their new wing. At the same time, the hotel cut promotional costs and focused on attracting millennial guests through digital marketing. As a result, although promotional costs were cut, promotions continued well and tended to increase. This study aimed to determine the effectiveness of implementing digital advertising at Grand Mirage Bali and how to increase the effectiveness of implementing digital advertising. Research data were collected through questionnaires and documentation studies. The collected datawere analyzed descriptively using AIDA analysis. The results showed (a) the digital advertising displayed by the Grand Mirage Resort Bali has been effective in its application as a sales promotion medium, and (b) the strategy to increase the effectiveness of the digital advertising at Grand Mirage Bali are paying attention to the message conveyed in the advertisement, using appealing visuals, choosing an ad theme that suits market conditions, and using marketing tricks such as giving limited offers.
\end{abstract}

Keywords: effectiveness, marketing 4.0, digital advertising, social media, website, AIDA

\begin{abstract}
Abstrak
Perkembangan industri mengalami evolusi dari pemasaran konvensional ke pemasaran berbasis digital, atau Marketing 4.0. Penggunaan media sosial sebagai alat promosi penting di zaman sekarang. Di industri hospitaliti, semakin banyak hotel mengembangkan profil mereka di media sosial secara intensif, di antaranya Grand Mirage Resort Bali. Pada awal tahun 2017 hotel telah selesai merenovasi dan rebranding wing baru mereka. Di waktu yang bersamaan, hotel memotong biaya promosi dan fokus untuk menggaet tamu milenial melalui pemasaran digital. Hasilnya, walaupun biaya promosi dipotong dan fokus pada promosi digital, promosi tetap berlangsung dengan baik dan cenderung mengalami peningkatan. Penelitian ini bertujuan untuk mengetahui efektivitas penerapan iklan digital di Grand Mirage Bali serta bagaimana meningkatkan efektivitas penerapan iklan digital di Grand Mirage Bali. Data penelitian dikumpulkan melalui kuesioner dan studi dokumentasi. Data yang sudah terkumpul dianalisis secara deskriptif menggunakan analisis AIDA. Hasil
\end{abstract}


penelitian menunjukkan (a) iklan digital yang ditampilkan oleh Hotel Grand Mirage Resort Bali sudah efektif dalam penerapannya sebagai media promosi penjualan, dan (b) strategi peningkatan efektivitas penerapan iklan digital di Grand Mirage Bali yaitu memperhatikan pesan yang disampaikan dalam iklan, menggunakan visual yang indah dan atraktif, memilih tema iklan yang sesuai dengan kondisi pasar, serta menggunakan iklan dan trik pemasaran seperti memberikan penawaran terbatas.

Kata kunci: efektivitas, marketing 4.0, iklan digital, media sosial, website, AIDA

\section{PENDAHULUAN}

Perkembangan industri mengalami evolusi dari pemasaran konvesional ke pemasaran berbasis digital atau dikenal dengan istilah marketing 4.0. Dari sudut pandang bisnis, media sosial dianggap sebagai alat dan platform yang efektif untuk memperdalam keterlibatan pelanggan dan meningkatkan interaksi pelanggan dengan bisnis (Sigala, 2012). Di industri hospitaliti, semakin banyak hotel membangun dan mengembangkan profil mereka di media sosial secara intensif (Chan dan Guillet, 2011).

Salah satu hotel yang menggunakan media sosial sebagai sarana pemasaran adalah Grand Mirage Resort Bali yang berlokasi di Tanjung Benoa, Bali. Berdasarkan hasil wawancara dengan salah satu e-commerce agent Hotel Grand Mirage Resort Bali, Ong Florentia Steryfanny, pada awal tahun 2017 hotel telah selesai merenovasi dan rebranding wing baru mereka yang diberi nama Family Paradise dengan total kamar 73 buah. Bersamaan dengan hal itu, hotel memotong biaya promosi dan memfokuskan untuk menggaet tamu-tamu milenial dengan kategori umur 20 sampai 40 tahun. Pemotongan biaya promosi dilakukan karena Hotel Grand Mirage Resort Bali merencanakan untuk melakukan renovasi di wing lama mereka. Maka dari itu, mereka memfokuskan untuk menjual kamar di wing baru dan sebagian wing lama.

Oleh karena itu, pihak Hotel Grand Mirage Resort Bali telah mempersiapkan tim $e$ commerce mereka untuk membangun profil media sosial mereka. Kegiatan branding profil dikhususkan melalui platform Facebook, karena platform tersebut menyediakan alat-alat analisis yang lengkap serta fasilitas yang memungkinkan pihak hotel berinteraksi langsung secara real time dengan calon pelanggan. Berikut Tabel 1.1 yang berisikan data biaya promosi dan pendapatan kamar Hotel Grand Mirage Resort Bali sebelum dan sesudah ditetapkannya digital advertising.

Tabel1: Perbandingan Biaya Promosi dan Pendapatan Kamar (dalam Rupiah) Sebelum dan Sesudah Diterapkan Digital Advertising Periode 2017 hingga 2019 di Hotel Grand Mirage Resort Bali

[Sumber: Sales and Marketing Department Hotel Grand Mirage Resort Bali, data diolah]

\begin{tabular}{ccc}
\hline Tahun & $\begin{array}{c}\text { Biaya Promosi } \\
\text { (Rp) }\end{array}$ & $\begin{array}{c}\text { Pendapatan } \\
\text { Kamar (Rp) }\end{array}$ \\
\hline 2017 & 252.102 .500 & 13.411 .857 .143 \\
2018 & 232.700 .000 & 14.720 .000 .000 \\
2019 & 240.120 .000 & 14.934 .166 .667 \\
\hline
\end{tabular}

Terlihat pada tahun 2018 biaya promosi mengalami penurunan namun pendapatan kamar cenderung mengalami peningkatan dibandingkan pada tahun 2017, sebelum hotel mulai menerapkan promosi digital marketing menggunakan media sosial. Hal ini menunjukkan bahwa walaupun biaya promosi dipotong dan diarahkan ke metode promosi digital, promosi tetap berlangsung secara efektif dan cenderung mengalami peningkatan. Berdasarkan hal tersebut, pihak hotel Grand Mirage Resort Bali juga 
menetapkan target pendapatan kamar yang baru. Adapun target dan realisasi pendapatan kamar Hotel Grand Mirage Resort Bali yang telah di rata-rata adalah sebagai berikut:

Tabel 2: Selisih Realisasi Target Pendapatan Kamar (dalam Rupiah)

Periode 2016 sampai 2019 di Hotel Grand Mirage Resort Bali

[Sumber: Sales and Marketing Department Hotel Grand Mirage Resort Bali, data diolah]

\begin{tabular}{lccc}
\hline Tahun & Realisasi (Rp) & $\begin{array}{c}\text { Target } \\
\text { (Rp) }\end{array}$ & Selisih \\
\hline 2016 & 13.936 .571 .429 & 14.362 .857 .143 & $(426.285 .714)$ \\
2017 & 13.411 .857 .143 & 14.664 .285 .714 & $(1.252 .428 .571)$ \\
2018 & 14.720 .000 .000 & 14.652 .208 .333 & 67.791 .667 \\
2019 & 14.934 .166 .667 & 14.853 .750 .000 & 80.416 .667 \\
\hline
\end{tabular}

Jika melihat secara spesifik data pada tiap bulannya, terjadi penurunan persentase selisih antara realisasi pendapatan kamar dengan target pendapatan kamar Hotel Grand Mirage Resort Bali setelah ditetapkannya strategi promosi berbasis media sosial. Maka dari itu, penting untuk mengetahui seberapa besar efektivitas iklan digital yang digunakan Grand Mirage Resort Bali, serta diperlukan pula strategi untuk meningkatkannya. Berdasarkan hal tersebut, penelitian ini bertujuan untuk mengetahui bagaimana efektivitas penerapan iklan digital yang dilakukan di Grand Mirage Resort Bali serta bagaimana strategi peningkatannya.

Novak dan Hoffman (1996) dalam Jain (2016) menunjukkan bukti empiris bahwa konsumen merespons iklan di Internet dengan cara yang sama ketika mereka menanggapi iklan di media tradisional. Port (1999) dalam Jain (2016) menyatakan Internet dan media interaktif lainnya seperti televisi dapat menyampaikan pesan lebih kuat, responsif, dan lebih mudah disesuaikan daripada media tradisional. Electronic-Word of Mouth (eWOM) didefinisikan sebagai "semua komunikasi informal yang diarahkan pada konsumen melalui teknologi berbasis Internet yang terkait dengan penggunaan atau karakteristik barang dan jasa tertentu, atau penjualnya" (Litvin, Goldsmith, \& Pan, 2008 dalam Leung, 2013). WOM dan $e W O M$ dapat berfungsi sebagai alat pemasaran dan hasil pemasaran (Hennig-Thurau, Gwinner, \& Gremler, 2002; Litvin et al., 2008 dalam Leung, 2013). Sebagai alat pemasaran, WOM dan eWOM sangat kuat dalam mempengaruhi sikap konsumen, evaluasi produk, loyalitas pelanggan, dan niat serta keputusan pembelian (Arndt, 1967; Chan \& Ngai, 2011; Litvin et al., 2008 dalam Leung).

Iklan internet adalah komunikasi komersil yang dimaksudkan menghasilkan respons dari waktu ke waktu. Pemahaman yang lebih baik tentang fungsi iklan internet tidak hanya akan membantu pengembangan dan penggunaan berbagai format iklan internet tetapi juga membantu integrasi efektif iklan tradisional dan internet dalam kampanye pemasaran (Kotler,2016: 24). Marketing 4.0 adalah pendekatan pemasaran yang menggabungkan interaksi online dan offline antar perusahaan dengan pelanggan. Dalam ekonomi digital, interaksi digital saja tidak cukup. Di dunia yang semakin terfokus pada online, tambahan sentuhan offline memberikan kesan yang berbeda terhadap sekadar interaksi online. Sangat penting bagi sebuah merek untuk lebih fleksibel dan adaptif karena tren teknologi yang cepat, namun karakter otentik mereka lebih penting daripada sebelumnya, karena di dunia yang transparan, keaslian karakter adalah aset yang paling berharga. Akhirnya, Marketing 4.0 memanfaatkan konektivitas internet dan kecerdasan buatan untuk meningkatkan produktivitas pemasaran sambil meningkatkan konektivitas manusia-ke-manusia untuk memperkuat keterlibatan pelanggan, mendorong hasil akhir, sedangkan marketing tradisional berfokus untuk memulai interaksi pelanggan (Kotler, 2016: 5). 
Dalam mengembangkan iklan yang efektif, idealnya iklan yang efektif tersebut harus memenuhi AIDA, yaitu: Menarik perhatian (attention), yang dapat diidentifikasi dengan menggunakan slogan yang mudah diingat dan menggunakan ukuran huruf merek dan slogan yang mudah dibaca konsumen serta menonjolkan kata-kata yang unik dan menjual.

Mengembangkan ketertarikan (interest), yang dapat diidentifikasi dengan berpenampilan menarik secara visual, menggunakan daya tarik tambahan seperti video dan musik dan menggunakan kata-kata yang mudah dipahami.

Membangkitkan keinginan (desire), yang dapat diidentifikasi dengan memberikan informasi yang jelas mengenai keunggulan produk, menampilkan alasan untuk mengkonsumsi produk dan membangkitkan keinginan untuk mengkonsumsi produk.

Menggerakkan tindakan (action), yang dapat diidentifikasi dengan Iklan sepenuhnya meyakinkan konsumen untuk menkonsumsi produk, Iklan produk membuat konsumen untuk sesegera mungkin melakukan pemesanan produk dan Iklan membuat konsumen tertarik untuk menyebarkan kepada orang lain.

AIDA merupakan tahapan dari tujuan iklan. Tujuan iklan yang utama adalah keputusan pembelian atau action (tindakan). AIDA dikenal pada tahun 1898, yang dikemukakan oleh Elias St. Elmo Lewis sebagai AID (attention, interest, desire). Dengan tujuan sebagai pedoman penjualan agar berhasil. Pada tahun 1900, E. St. Elmo Lewis mengembangkan AID menjadi AIDA dengan menambahkan action untuk pedoman penjualan yang awalnya menargetkan konsumen berprospek menjadi proses penjualan yang sempurna (Barry and Howard, 1990 dalam Wijaya, 2011). Kesimpulannya suatu iklan bisa dikatakan iklan yang efektif bila telah memenuhi AIDA sehingga mendorong keterlibatan konsumen.

\section{METODE PENELITIAN}

Objek penelitian ini adalah efektivitas penggunaan iklan berbasis digital marketing di Hotel Grand Mirage Resort Bali. Lokasi penelitian ini bertempat di Hotel Grand Mirage Resort Bali. Jenis data yang digunakan pada penelitian ini adalah data kuantitatif dan kualitatif. Data yang digunakan dalam penelitian ini menurut sumbernya adalah data primer dan sekunder, yakni data tingkat pendapatan kamar dan biaya promosi untuk data sekunder, dan data primer yang diperoleh melalui kuesioner tentang bagaimana penerapan iklan digital yang digunakan oleh Hotel Grand Mirage Resort Bali.

Populasi penelitian ini adalah jumlah followers aktif akun media sosial Facebook dan Instagram Grand Mirage Resort Bali, yakni berjumlah 2257 followers. Dalam penelitian ini digunakan teknik purposive sampling, kriteria penentuan sampel dalam penelitian yaitu pengguna media sosial dan mengetahui informasi mengenai Hotel Grand Mirage Resort Bali melalui media sosial Facebook, Instagram dan website Hotel Grand Mirage Resort Bali, berpendidikan minimal SMA/SMK dan berusia antara 20 sampai 40 tahun.

Pada penentuan ukuran sampel yang akan digunakan menggunakan rumus Slovin dalam Sugiyono (2013):

$$
n=\frac{N}{1+N R^{2}}
$$

dimana $\mathrm{n}$ adalah ukuran sampel, $\mathrm{N}$ adalah ukuran populasi, dan e adalah kelonggaran ketidaktelitian atau derajat toleransi [1]. Derajat toleransi yang ditentukan sebesar 10\%, sehingga memberikan hasil jumlah sampel penelitian minimal 95,75 atau dibulatkan menjadi 96. Untuk mengantisipasi resiko terjadinya kuesioner yang tidak layak untuk diolah, maka dalam penelitian ini akan disebarkan sebanyak 150 kuesioner. Teknik pengumpulan data yang digunakan adalah kuesioner yang menggunakan 12 indikator AIDA dengan metode penilaian Skala Likert 1-5 dan studi dokumentasi yakni data tingkat pendapatan kamar dan biaya promosi. Teknik analisis yang digunakan dalam penelitian 
ini yaitu analisis AIDA (attention, interest, desire dan action). Menurut Paulus (2011) metode analisis AIDA menggunakan rumus sebagai berikut.

$$
\mathrm{X}=\frac{\text { Total Nilai } \quad \mathrm{x} 100 \%}{\text { Total nilai penuh harapan } \mathrm{Xn}}
$$

dimana X adalah nilai pada masing-masing tahapan AIDA [2]. Untuk selanjutnya pengukuran efektivitasnya dikelompokkan ke dalam lima kelompok menurut Paulus(2011), sebagai berikut:

Tabel 3: Tabel Kategori Efektivitas Iklan Digital Sumber: [Paulus, 2011]

\begin{tabular}{lcc}
\hline No. & Persentase & $\begin{array}{c}\text { Kategori } \\
\text { Efektivitas }\end{array}$ \\
\hline 1. & $0-20 \%$ & Buruk \\
2. & $21-40 \%$ & Menengah \\
3. & $41-60 \%$ & Rata-rata \\
4. & $61-80 \%$ & Baik \\
5. & $81-100 \%$ & Istimewa \\
\hline
\end{tabular}

\section{HASIL DAN PEMBAHASAN}

\subsection{Deskripsi Data}

Dari total 150 kuesioner yang disebarkan, yang memenuhi syarat yaitu sebanyak 145 kuesioner. Selanjutnya data diolah berdasarkan kuesioner yang sudah terkumpul. Berikut merupakan rincian karakteristik responden berdasarkan jenis kelamin, rentang usia, pendidikan terakhir, dan pekerjaan.

Tabel 4: Karakteristik responden berdasarkan jenis kelamin Sumber: [Data primer, 2020 (diolah)]

\begin{tabular}{lcc}
\hline Jenis Kelamin & Jumlah & Persentase(\%) \\
\hline Laki-laki & 55 & 37 \\
Perempuan & 90 & 62 \\
\hline Total & 145 & 100 \\
\hline
\end{tabular}

Tabel 4 menunjukkan bahwa berdasarkan jenis kelamin, jumlah responden perempuan lebih banyak dibandingkan dengan responden laki-laki yaitu sebesar 90 orang responden perempuan atau $62 \%$ dari total responden dan 55 orang responden laki-laki atau $37 \%$ dari total responden.

Tabel 5: Karakteristik responden berdasarkan usia Sumber: [Data primer, 2020 (diolah)]

\begin{tabular}{lcc}
\hline Usia & Jumlah & Persentase(\%) \\
\hline $20-30$ & 72 & 50 \\
$31-40$ & 73 & 50 \\
\hline Total & 145 & 100 \\
\hline
\end{tabular}


Pada tabel 5 tampak bahwa berdasarkan usia, distribusi responden didominasi oleh pelanggan yang berusia antara 21-30 tahun sebanyak 72 orang dengan persentase $50 \%$. Diikuti dengan responden yang berusia antara 31-40 tahun sebanyak 73 orang atau $50 \%$.

Tabel 6: Karakteristik responden berdasarkan pendidikan terakhir Sumber: [Data primer, 2020 (diolah)]

\begin{tabular}{lcc}
\hline $\begin{array}{l}\text { Pendidikan } \\
\text { Terakhir }\end{array}$ & Jumlah & Persentase(\%) \\
\hline SMA/SMK & 37 & 26 \\
Diploma & 18 & 12 \\
Sarjana & 85 & 59 \\
Pascasarjana & 5 & 3 \\
\hline Total & 145 & 100 \\
\hline
\end{tabular}

Tabel 6 menunjukkan bahwa berdasarkan jenjang pendidikan terakhir, jumlah responden didominasi oleh lulusan sarjana dengan jumlah 85 orang dengan persentase 59\%. Diikuti dengan lulusan SMA/SMK dengan jumlah 37 orang atau 26\%, kemudian lulusan diploma dengan jumlah 18 orang atau $12 \%$ dan lulusan pascasarjana dengan lima responden atau 3\% dari total responden.

Tabel 7: Karakteristik responden berdasarkan pekerjaan Sumber: [Data primer, 2020 (diolah)]

\begin{tabular}{lcc}
\hline Pekerjaan & Jumlah & Persentase(\%) \\
\hline Wiraswasta & 38 & 27 \\
Pegawai Swasta & 107 & 73 \\
\hline Total & 145 & 100 \\
\hline
\end{tabular}

Tabel 7 menunjukkan bahwa berdasarkan pekerjaan, jumlah responden didominasi oleh pegawai swasta dengan jumlah 107 orang atau 73\% dari total responden, diikuti dengan 38 orang responden wiraswasta atau $27 \%$.

Dengan mengumpulkan kuesioner sebanyak 145 eksemplar menggunakan Skala Likert dalam penilaiannya, kuesioner yang dibagikan bernilai:

1 = Sangat Tidak Setuju (STS) diberi bobot 1

2 = Tidak Setuju (TS) diberi bobot 2

$3=\operatorname{Netral}(\mathrm{N})$ diberi bobot 3

4 = Setuju (S) diberi bobot 4

5 = Sangat Setuju (SS) diberi bobot 5

Tabel-tabel berikut akan menampilkan tabulasi jawaban responden menurut masing-masing tahapan AIDA.

Tabel 8: Penilaian Responden Terhadap Pernyataan Attention Sumber: [Data primer, 2020 (diolah)]

\begin{tabular}{|c|c|c|c|c|c|c|c|}
\hline \multirow{2}{*}{ No } & \multirow{2}{*}{ Daftar Pernyataan } & \multicolumn{5}{|c|}{ Jawaban Responden } & \multirow{2}{*}{$\begin{array}{c}\text { Jawaban Rata- } \\
\text { rata }\end{array}$} \\
\hline & & 5 & 4 & 3 & 2 & 1 & \\
\hline 1 & Iklan menggunakan slogan yang mudah saya ingat & 92 & 40 & 10 & 2 & 1 & 4,51 \\
\hline 2 & $\begin{array}{l}\text { Saya dengan mudah dapat membaca huruf merek } \\
\text { dan slogan iklan }\end{array}$ & 88 & 44 & 10 & 2 & 1 & 4,49 \\
\hline
\end{tabular}




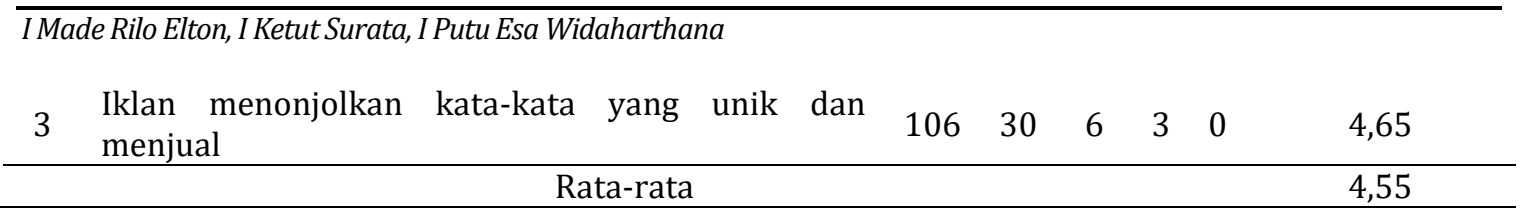

Tabel 8 menunjukkan hasil jawaban responden terhadap tiga pernyataan kuesioner mengenai dimensi Attention oleh 145 responden. Nilai rata-rata terhadap penilaian kuesioner tersebut berada pada rentang nilai 4,55. Nilai tertinggi terdapat pada pernyataan kuesioner butir ketiga mengenai "Iklan menonjolkan kata-kata yang unik dan menjual" dengan rata-rata nilai sebesar 4,65. Sedangkan nilai terendah terdapat pada butir kedua mengenai "Saya dengan mudah dapat membaca huruf merek dan slogan iklan" dengan rata-rata skor sebesar 4,49.

Tabel 9: Penilaian Responden Terhadap Pernyataan Interest Sumber: [Data primer, 2020 (diolah)]

\begin{tabular}{|c|c|c|c|c|c|c|c|}
\hline \multirow{2}{*}{ No } & \multirow{2}{*}{ Daftar Pernyataan } & \multicolumn{5}{|c|}{ Jawaban Responden } & \multirow{2}{*}{$\begin{array}{c}\text { Jawaban Rata- } \\
\text { rata }\end{array}$} \\
\hline & & 5 & 4 & 3 & 2 & 1 & \\
\hline 1 & \multirow{2}{*}{$\begin{array}{l}\text { Penampilan iklan menarik secara visual } \\
\text { Iklan menggunakan daya tarik tambahan seperti } \\
\text { video atau music }\end{array}$} & 106 & 31 & 8 & 0 & 0 & 4,67 \\
\hline 2 & & 110 & 30 & 5 & 0 & 0 & 4,72 \\
\hline 3 & $\begin{array}{l}\text { Iklan menggunakan kata-kata yang mudah saya } \\
\text { pahami }\end{array}$ & 113 & 23 & 8 & 1 & 0 & 4,71 \\
\hline \multicolumn{7}{|c|}{ Rata-rata } & 4,70 \\
\hline
\end{tabular}

Tabel 9 menunjukkan hasil jawaban responden terhadap tiga pernyataan kuesioner mengenai dimensi Interest oleh 145 responden. Nilai rata-rata terhadap penilaian kuesioner tersebut berada pada rentang nilai 4,70. Nilai tertinggi terdapat pada pernyataan kuesioner butir kedua mengenai "Iklan menggunakan daya tarik tambahan seperti video atau musik" dengan rata-rata nilai sebesar 4,72. Sedangkan nilai terendah terdapat pada butir pertama mengenai "Penampilan iklan menarik secara visual" dengan rata-rata skor sebesar 4,67.

Tabel 10: Penilaian Responden Terhadap Pernyataan Desire Sumber: [Data primer, 2020 (diolah)]

\begin{tabular}{|c|c|c|c|c|c|c|c|}
\hline \multirow{2}{*}{ No } & \multirow{2}{*}{ Daftar Pernyataan } & \multicolumn{5}{|c|}{ Jawaban Responden } & \multirow[t]{2}{*}{$\begin{array}{l}\text { Jawaban } \\
\text { Rata-rata }\end{array}$} \\
\hline & & 5 & 4 & 3 & 2 & 1 & \\
\hline 1 & $\begin{array}{l}\text { Terdapat informasi yang jelas mengenai keunggulan } \\
\text { hotel }\end{array}$ & 93 & 45 & 7 & 0 & 0 & 4.59 \\
\hline 2 & $\begin{array}{l}\text { Iklan menampilkan alasan mengapa saya harus } \\
\text { menginap di Hotel Grand Mirage Resort Bali }\end{array}$ & 90 & 47 & 6 & 2 & 0 & 4,55 \\
\hline 3 & $\begin{array}{l}\text { Iklan membangkitkan keinginan saya untuk menginap } \\
\text { di Grand Mirage Resort Bali }\end{array}$ & 92 & 47 & 6 & 0 & 0 & 4,55 \\
\hline & $\begin{array}{ll} & \text { Rata-rata } \\
\end{array}$ & & & & & & 4,57 \\
\hline
\end{tabular}

Tabel 10 menunjukkan hasil jawaban responden terhadap tiga pernyataan kuesioner mengenai dimensi Desire oleh 145 responden. Nilai rata-rata terhadap penilaian kuesioner tersebut berada pada rentang nilai 4,57. Nilai tertinggi terdapat pada pernyataan kuesioner butir pertama mengenai "Terdapat informasi yang jelas mengenai keunggulan hotel" dengan rata-rata nilai sebesar 4,59. Sedangkan nilai terendah terdapat pada butir pertama mengenai "Iklan menampilkan alasan mengapa saya harus menginap di Hotel Grand Mirage Resort Bali” dengan rata-rata skor sebesar 4,55. 
Tabel 11: Penilaian Responden Terhadap Pernyataan Action Sumber: [Data primer, 2020 (diolah)]

\begin{tabular}{|c|c|c|c|c|c|c|c|}
\hline \multirow{2}{*}{ No } & \multirow{2}{*}{ Daftar Pernyataan } & \multicolumn{5}{|c|}{ Jawaban Responden } & \multirow{2}{*}{$\begin{array}{l}\text { Jawaban } \\
\text { Rata-rata }\end{array}$} \\
\hline & & 5 & 4 & 3 & 2 & 1 & \\
\hline 1 & $\begin{array}{l}\text { Iklan produk hotel membuat saya merasa yakin } \\
\text { sepenuhnya untuk menginap di Hotel Grand Mirage } \\
\text { Resort Bali }\end{array}$ & 83 & 46 & 15 & 1 & 0 & 4,45 \\
\hline 2 & $\begin{array}{l}\text { Iklan produk hotel membuat saya sesegera mungkin } \\
\text { melakukan pemesanan untuk menginap di Hotel Grand } \\
\text { Mirage Resort Bali }\end{array}$ & 69 & 46 & 25 & 4 & 1 & 4,22 \\
\hline 3 & $\begin{array}{l}\text { Saya tertarik untuk menyebarkan iklan yang baru saja } \\
\text { saya lihat kepada kerabat saya }\end{array}$ & 80 & 42 & 19 & 3 & 1 & 4,35 \\
\hline & Rata-rata & & & & & & 4,34 \\
\hline
\end{tabular}

Tabel 11 menunjukkan hasil jawaban responden terhadap tiga pernyataan kuesioner mengenai dimensi Action oleh 145 responden. Nilai rata-rata terhadap penilaian kuesioner tersebut berada pada rentang nilai 4,34. Nilai tertinggi terdapat pada pernyataan kuesioner butir pertama mengenai "Iklan produk hotel membuat saya merasa yakin sepenuhnya untuk menginap di Hotel Grand Mirage Resort Bali" dengan rata-rata nilai sebesar 4,45 . Sedangkan nilai tekecil terdapat pada butir kedua mengenai "Iklan produk hotel membuat saya sesegera mungkin melakukan pemesanan untuk menginap di Hotel Grand Mirage Resort Bali" dengan rata-rata skor sebesar 4,22.

\subsection{Pembahasan}

Ditinjau dari model analisis AIDA yaitu dimensi attention memiliki total nilai 1980, dimensi interest memiliki total nilai 2046, dimensi desire memiliki total nilai 1992, dan dimensi action mendapat nilai 1891. Untuk total nilai harapan pada tiap dimensi memiliki nilai yang sama, yaitu $5 \times 3 \times 145=2175$, dimana total nilai harapan diperoleh dari nilai jawaban kuesioner tertinggi 5, dikalikan dengan 3 pertanyaan di tiap dimensi AIDA, lalu dikalikan dengan jumlah total responden. Selanjutnya, sesuai dengan rumus (2), maka diperoleh hasil sebagai berikut.

Tabel 12: Hasil Perhitungan Efektivitas Iklan Digital di Masing-masing Tahapan AIDA Sumber: [Data primer, 2020 (diolah)]

\begin{tabular}{clcccc}
\hline \multirow{2}{*}{ No } & \multirow{2}{*}{ Dimensi } & \multicolumn{2}{c}{ Nilai Efektivitas } & Persentase Efektivitas & Kategori Efektivitas \\
\cline { 3 - 5 } & Kuesioner & Harapan & & \\
\hline 1 & Attention & 1980 & & $91 \%$ & Istimewa \\
2 & Interest & 2046 & \multirow{2}{*}{2175} & $94 \%$ & Istimewa \\
3 & Desire & 1992 & & $92 \%$ & Istimewa \\
4 & Action & 1891 & & $86 \%$ & Istimewa \\
\hline
\end{tabular}

Pada Tabel 12 dipaparkan bahwa hasil yang didapatkan berbeda-beda tiap dimensi. Dimensi pertama yaitu attention mendapatkan hasil persentase efektivitas sebanyak $91 \%$, dimensi kedua yaitu interest mendapatkan hasil persentase efektivitas sebanyak $94 \%$, dimensi ketiga yaitu desire mendapatkan hasil persentase efektivitas sebanyak 92\%, dan dimensi keempat yaitu action mendapatkan hasil persentase efektivitas sebanyak $86 \%$. Berdasarkan hasil tersebut, dimensi interest mendapatkan nilai tertinggi yaitu sebanyak 94\% dan dimensi action mendapatkan nilai terendah yaitu sebanyak $86 \%$. Berdasarkan Paulus (2011), keempat dimensi tersebut termasuk dalam kategori "istimewa" karena persentase efektivitas yang didapat oleh semua dimensi berada diantara $81-100 \%$. 
Berdasarkan analisis yang telah diuraikan maka strategi yang dapat dirumuskan menurut masing-masing dimensi AIDA adalah sebagai berikut.

Attention; memperhatikan pesan yang disampaikan dalam iklan agar iklan mampu mendapat perhatian, minat, menimbulkan keinginan dan mempengaruhi keputusan calon pelanggan. Pemilihan bentuk dan ukuran tulisan yang digunakan pada iklan juga mempengaruhi minat calon pelanggan. Sebaiknya tulisan dibuat kontras, mudah dibaca dan tidak terlalu panjang. Dengan visual berupa sudut hunian dan bentuk fasilitas, apa yang ditonjolkan akan lebih efektif daripada sekedar tulisan.

Interest; mempertimbangkan kegiatan periklanan yang lebih efektif agar lebih mengkomunikasikan produk kepada calon pelanggan secara menyeluruh. Iklan suatu produk yang menggunakan visual yang indah dan atraktif akan lebih menarik termasuk pemilihan musik dan editing yang halus atas video yang ditampilkan. Hal tersebut mampu meningkatkan minat calon pelanggan bahkan tamu langganan agar senantiasa mengingat momen terbaik mereka saat menginap di Hotel Grand Mirage Resort Bali dan memutuskan untuk kembali lagi di lain waktu.

Desire; memilih tema iklan yang sesuai dengan kondisi pasar dalam hal ini keinginan calon pelanggan, seperti menampilkan fasilitas unik yang tidak akan mereka temui di hunian lain yang tentu saja menambah nilai jual tersendiri bagi Hotel Grand Mirage Resort.

Action; menggunakan iklan dan trik pemasaran tepat seperti memberikan penawaran terbatas untuk menikmati momen yang hanya diadakan di Hotel Grand Mirage Resort Bali pada waktu tertentu. Misalnya bekerja sama dengan koki terkenal atau selebritas terkenal, tamu bisa menikmati cooking class atau momen langka dan pastinya seru hanya di Hotel Grand Mirage Resort Bali. Hal ini memungkinkan calon pelanggan akan segera melakukan pemesanan untuk menikmati momen yang ditawarkan tersebut atau bahkan mengajak sahabat dan keluarga mereka untuk ikut menikmatinya di Hotel Grand Mirage Resort Bali. Bahkan hal terbaik lainnya adalah mereka akan dengan senang hati membagikan pengalaman luar biasa mereka kepada khalayak ramai.

\section{KESIMPULAN}

Iklan digital yang ditampilkan oleh Hotel Grand Mirage Resort Bali melalui media sosial Facebook dan Instagram serta website sudah efektif dalam penerapannya sebagai media promosi penjualan. Hal ini dilihat dari model analisis AIDA, yang menunjukkan bahwa tahapan attention berada di tingkatan istimewa, dengan persentase efektivitas sebesar 91\%. Tahapan interest berada di tingkatan istimewa, dengan persentase efektivitas sebesar 94\%. Tahapan desire berada di tingkatan istimewa, dengan persentase efektivitas sebesar 92\%. Tahapan action berada di tingkatan istimewa, dengan persentase efektivitas sebesar $86 \%$.

Strategi peningkatan efektivitas penerapan iklan digital di hotel Grand Mirage Bali diantaranya memperhatikan pesan yang disampaikan dalam iklan agar tulisan dibuat kontras, mudah dibaca dan tidak terlalu Panjang, menggunakan visual yang indah dan atraktif, seperti pemilihan musik dan editing yang halus atas video yang ditampilkan, memilih tema iklan yang sesuai dengan kondisi pasar, seperti menampilkan fasilitas unik yang tidak akan mereka temui di hunian lain, dan menggunakan trik pemasaran seperti memberikan penawaran terbatas untuk menikmati momen yang hanya diadakan di Hotel Grand Mirage Resort Bali pada waktu tertentu.

\section{PERNYATAAN PENGHARGAAN}

Penulis mengucapkan terimakasih sebesar-besarnya kepada narasumber penelitian yaitu e-commerce agent Hotel Grand Mirage Resort Bali, Ong Florentia Steryfanny beserta seluruh sales team lainnya, para responden yang telah berpartisipasi dalam penelitian ini, 
seluruh tenaga kependidikan atas semua bantuan dan bimbingan yang diberikan selama penulis menempuh studi di Politeknik Pariwisata Bali, serta semua pihak lain yang membantu pelaksanaan penelitian ini yang tidak dapat penulis sebutkan satu-persatu.

\section{DAFTAR PUSTAKA}

Arndt, J. (1967). Role of product-related conversations in the diffusion of a new product. Journal of Marketing Research, 4, 291-295.

Barry, T. E. \& Howard, D. J. (1990). A Review and Critique of The Hierarchy of Effects in Advertising. International Journal of Advertising, 9 (2), 98-111.

Chan, N. L. \& Guillet, B. D. (2011). Investigation of Social Media Marketing: How Does the Hotel Industry in Hong Kong Perform in Marketing on Social Media Websites?. Journal of Travel \& Tourism Marketing, 28(4):345-368. DOI:10.1080/10548408.2011.571571.

Chan, Y. Y., \& Ngai, E. W. T. (2011). Conceptualising electronic word of mouth activity: An input-process-output perspective. Marketing Intelligence \& Planning, 29, 488-516.

Hennig-Thurau, T., Gwinner, K. P., \& Gremler, D. D. (2002). Understanding relationship marketing outcomes: An integration of relational benefits and relationship quality. Journal of Service Research, 4, 230-247.

Jain, P., Karamchandani, M. \& Jain, A. (2016). Effectiveness of Digital Advertising. Advances in Economics and Business Management (AEBM), 3 (5), 490-495.

Kotler, P., Kartajaya, H. \& Setiawan, I. (2016). Marketing 4.0. New Jersey:Wiley.

Leung, X. Y., Bai, B. \& Stahura, K. A. (2013). The Marketing Effectiveness of Social Media in the Hotel Industry:A Comparison of Facebook and Twitter. Journal of Hospitality \& Tourism Research, 20 (10).

Litvin, S. W., Goldsmith, R. E. \& Pan, B. (2008). Electronic word-of-mouth in hospitality and tourism management. Tourism Management, 29, 458-468.

Novak, T. P. \& Hoffman, D. L. (1996). Marketing in Computer-Mediated Environments: Conceptual Foundations. Journal of Marketing, 60, 50-68.

Paulus, L. K. (2011). Psikologi Pemasaran. Jakarta: PT. Buku Seru.

Port, O. (1999). Customers Move Into the Driver's Seat. Business Week, 103-106.

Sigala, M. (2012). Social networks and customer involvement in new service development (NSD): The case of www.mystarbucksidea.com. International Journal of Contemporary Hospitality Management, 24 (7), 966-990.

Sugiyono. (2013). Metode Penelitian Kuantitatif, Kualitatif dan $R \& D$. Cetakan Kesembilan Belas. Bandung:Alfabeta.

Wijaya, B. S. (2012). The Development of Hierarchy of Effects Model in Advertising. International Research Journal of Business Studies (IRJBS), 5 (1). 